\title{
Mussel-inspired biocompatible polydopamine/carboxymethyl cellulose/polyacrylic acid adhesive hydrogels with UV-shielding capacity
}

\author{
Zuwu Tang $\cdot$ Yanan Miao $\cdot$ Jing Zhao $\cdot$ He Xiao $\cdot$ Min Zhang $\cdot$ \\ Kai Liu $\cdot$ Xingye Zhang $\cdot$ Liulian Huang $\cdot$ Lihui Chen $\cdot$ Hui Wu $(1)$
}

Received: 25 July 2020/ Accepted: 17 November 2020/Published online: 2 January 2021

(C) Springer Nature B.V. 2021

\begin{abstract}
Hydrogels are attractive due to their various applications in the fields of biomedical materials, cosmetics, and biosensors. To enhance UV protection and prevent skin penetration behaviors, inspired by the mussel adhesive proteins, the functional polydopamine (PDA) is employed herein to fabricate polydopamine/carboxymethyl cellulose/ polyacrylic acid (PDA/CMC/PAA) adhesive hydrogels. To disperse PDA nanoparticles well in the PAA matrix, dopamine was self-polymerized in $\mathrm{CMC}$ solution to form PDA/CMC complex. Acrylic acid was polymerized in PDA/CMC complex solution and cross-linked to construct UV-resistant PDA/CMC/ PAA hydrogel. The morphology, rheological
\end{abstract}

Z. Tang $\cdot$ Y. Miao $\cdot$ J. Zhao $\cdot$ H. Xiao $(\bowtie) \cdot$

M. Zhang $\cdot$ K. Liu $\cdot$ X. Zhang $(\bowtie)$.

L. Huang $\cdot$ L. Chen $\cdot$ H. Wu ( $₫)$

College of Material Engineering, Fujian Agriculture and

Forestry University, No. 63, Xiyuangong Road, Minhou

District, Fuzhou 350108, Fujian, People's Republic of

China

e-mail: xiaohe_river@163.com

X. Zhang

e-mail: zhang.xingye@hotmail.com

H. Wu

e-mail:wuhui@fafu.edu.cn

Z. Tang $\cdot$ Y. Miao $\cdot$ H. Xiao $\cdot$ M. Zhang $\cdot$

K. Liu · L. Huang · L. Chen · H. Wu

National Forestry and Grassland Administration Key

Laboratory of Plant Fiber Functional Materials,

Fuzhou 350108, Fujian, People's Republic of China behavior, mechanical properties and adhesion strength of PDA/CMC/PAA hydrogels were studied by scanning electron microscopy, rotational rheometer, universal test machine. Owing to the hydrogen bonding interaction between the PDA/CMC complex and PAA, the PDA/CMC/PAA hydrogels showed high resilience and compressive strength to withstand large deformation. The hydrogels exhibited strong adhesion to various substrate surfaces, such as stainless steel, aluminum, glass and porcine skin. The biocompatibility and UV-shielding properties were investigated through culture of cells and UV irradiation test. The adhesiveness of PDA promoted cell adhesion and provided the PDA/CMC/PAA hydrogels good biocompatibility with $96 \%$ of relative cell viability. The hydrogels possessed excellent UV-shielding ability to prevent collagen fibers from being destroyed during UV irradiation, which has promising potential in the practical applications for UV filtration membrane and skin care products.

Keywords Adhesive - Biocompatibility $\cdot$ Hydrogel . Polydopamine $\cdot$ UV-shielding

\section{Introduction}

The main ultraviolet (UV) source in nature is the sun, which sends a huge amount of UV ray to the earth 
every day. Over-exposure of UV radiation can cause severe negative effects on human health, such as sunburn, skin aging, and skin cancers (Corbyn 2014; Dickerson et al. 1997; Noonan et al. 2001). The development of UV-shielding material has attracted much attention. At present, organic filters (octinoxate and avobenzone) and inorganic particulate filters ( $\mathrm{ZnO}$ and $\mathrm{TiO}_{2}$ particles) were extensively utilized as commercial UV-resistant materials (Baker et al. 2017). However, organic filters often suffer from potential toxicity and endocrine disruption because of the permeation across human skin (Hayden et al. 2005). Meanwhile they also suffer from problems such as photodegradation (Abdelraheem et al. 2015). Inorganic particulate filters can not only generate the reactive oxygen species to damage tissues or DNA (Pan et al. 2009; Trouiller et al. 2009), but also show obvious photocatalytic effects to degrade polymer matrices (Yu et al. 2002).

Recently, polydopamine (PDA) was widely used as a versatile material in the applications of coatings, sensors, and medicine (Cheng et al. 2019; Faure et al. 2013; Lee et al. 2007; Patil et al. 2018; Zhang et al. 2019). Dopamine (DA) is an amino acid in mussel adhesive proteins with strong adhesion to various surface (Cui et al. 2018). DA is easy to polymerize under basic condition to form PDA nanoparticles. PDA nanoparticles facilitate cell adhesion through conjunction with various reactive groups on cell membranes, such as amino groups and phenolic hydroxyl groups (Wang et al. 2016a, b, c). PDA has the similar physical and chemical properties to eumelanins (Wang et al. 2017), which could resist the UV rays by scavenging free radical, enhance UV protection, and prevent skin penetration behaviors $(\mathrm{Ju}$ et al. 2011; Liu et al. 2017). Thus, the promising features turn PDA-containing gel into ideal candidate for the safe and efficient UV-shielding materials (Han et al. 2018a, b; Wang et al. 2018). In the past decades, hydrogels have emerged as a fascinating material for various applications in the chemical and biomedical fields (Hoffman 2012; Lee and Mooney 2001). It is anticipant to incorporate PDA nanoparticles into polymer matrix to develop hydrogel with superior UV shielding capacity. However, nanoparticles are known to be prone to aggregate and not easy to disperse in solution, which affect the uniformity of product and limits its application.
Cellulose is a sustainable material in nature to produce functional derivatives (Klemm et al. 2005; Sun et al. 2018; Tang et al. 2020; Wang et al. 2016a, b, c; Wang et al. 2019a, b; Wu et al. 2018, 2020; Xiao et al. 2020; Zhou et al. 2016; Zhuo et al. 2016). For example, water-soluble carboxymethyl cellulose (CMC) with high biocompatibility, biodegradability, and low immunogenicity, can be prepared by etherification of alkali cellulose with monochloroacetic acid/sodium salt (Heinze and Pfeiffer 1999; Kirk and Othmer 1967). Because of thickening, adhesion, water retention, emulsification and suspension, CMC is widely used in petroleum, food, medicine, textile and papermaking industries (Grządka et al. 2020; Ikechukwu Ugwoke et al. 2000; Shen et al. 2010). Due to the functional carboxyl groups in $\mathrm{CMC}$, it is expected that $\mathrm{CMC}$ has strong interactions with PDA to construct PDA/CMC complex. The hydrogen bonding between the carboxyl groups in CMC and catechol groups and amino groups in PDA could disperse the functional PDA nanoparticles in solution and further promote the application of CMC and PDA. Meanwhile, polyacrylic acid (PAA) is a biocompatible polymer (Yin et al. 2016) with plenty of carboxyl groups, which is widely used as the matrix of hydrogel with appropriate mechanical properties. Those motivate us to fabricate the biocompatible adhesive PDA/CMC/PAA hydrogel for UV-shielding.

In this work, UV-resistant PDA/CMC/PAA hydrogels were fabricated by incorporation of PDA/CMC complex into PAA matrix. PDA/CMC complex were formed by self-polymerizing dopamine in CMC solutions. PDA/CMC/PAA hydrogels were constructed by cross-linking acrylic acid in well-dispersed PDA/CMC complex solution. The structure, rheological behavior, mechanical properties, swelling behaviors, adhesion strength, biocompatibility, and UVshielding performance of the PDA/CMC/PAA hydrogels were investigated.

\section{Experiments}

\section{Materials}

Dopamine hydrochloride, carboxymethyl cellulose (CMC), acrylic acid (AA), potassium persulfate (KPS), $N, N^{\prime}$-methylene bisacrylamide (MBA), and 
sodium hydroxide $(\mathrm{NaOH})$ were purchased from Aladdin. NIH 3T3 cells were obtained from Procell Life Science and Technology Co., Ltd. Fetal bovine serum (FBS) was supplied by Gibco. All chemicals were of reagent grade. Porcine skin was purchased from local grocery store. Ultrapure water $(18.2 \mathrm{M} \Omega \mathrm{cm}$ ) obtained by a water purifier (Sichuan Water Purifier Co. Ltd., China) was used for all experiments.

\section{Hydrogel preparation}

The PDA/CMC/PAA hydrogels with various PDA contents were prepared as follows. Firstly, $0.25 \mathrm{~g}$ of CMC was dissolved in $10 \mathrm{~mL}$ of ultrapure water. A determined amount of DA was subsequently added to the CMC solution and stirred for $30 \mathrm{~min}$ to achieve desired PDA contents. Secondly, the $\mathrm{pH}$ of the DA/ $\mathrm{CMC}$ mixture solution was adjusted to 10 using $0.5 \mathrm{M}$ $\mathrm{NaOH}$, and stirred for $30 \mathrm{~min}$ to allow DA to selfpolymerize to form a PDA/CMC complex. Thirdly, $5.0 \mathrm{~g}$ of AA, $0.025 \mathrm{~g}$ of KPS and $0.05 \mathrm{~g}$ of MBA were added to the PDA/CMC complex solution. AA was polymerized and cross-linked to construct PDA/CMC/ PAA hydrogel at $80{ }^{\circ} \mathrm{C}$ for $10 \mathrm{~min}$ (Fig. 1) (Han et al. $2018 \mathrm{a}, \mathrm{b})$. The hydrogels prepared using 0.01, 0.02, 0.04 , and $0.08 \mathrm{~g}$ of PDA, were denoted as $\mathrm{PDA}_{0.01} /$ CMC/PAA, $\quad \mathrm{PDA}_{0.02} / \mathrm{CMC} / \mathrm{PAA}, \quad \mathrm{PDA}_{0.04} / \mathrm{CMC} /$ $\mathrm{PAA}, \mathrm{PDA}_{0.08} / \mathrm{CMC} / \mathrm{PAA}$, respectively. For comparison, the PAA hydrogel was prepared by the polymerization of $5.0 \mathrm{~g}$ of $\mathrm{AA}$ and $0.05 \mathrm{~g}$ of $\mathrm{MBA}$ in $10 \mathrm{~mL}$ of water containing $0.025 \mathrm{~g}$ of $\mathrm{KPS}$ at $80^{\circ} \mathrm{C}$ for $10 \mathrm{~min}$.

\section{Characterization of the hydrogels}

The UV-shielding properties of hydrogels were characterized by an UV-Vis spectrophotometer (Agilent 8453, USA). Prior to UV measurement, the hydrogels were soaked in ultrapure water for $24 \mathrm{~h}$. PAA hydrogel and PDA/CMC/PAA hydrogels were cut into small cuboids with thickness of $1 \mathrm{~mm}$ and width of $4 \mathrm{~mm}$ to ensure the same PAA content.

Infrared spectra were recorded on a FTIR (BRUKER TENSOR II, Germany) spectrometer. The freeze-dried samples were pressed into a sheet using $\mathrm{KBr}$ powder. All spectra were recorded in the wavenumber ranging from 4000 to $400 \mathrm{~cm}^{-1}$ with a resolution of $4 \mathrm{~cm}^{-1}$.
The hydrogels were measured by X-ray photoelectron spectroscopy (XPS, Thermo Scientific ESCALAB 250Xi, USA), with a standard Al $K \alpha$ X-ray source. The X-ray beam was operated at a current of $10 \mathrm{~mA}$ and an acceleration voltage of $15 \mathrm{kV}$. For wide scan spectra, energy ranging from 0 to $1000 \mathrm{eV}$ was used with a pass energy of $100 \mathrm{eV}$ and step of $1.0 \mathrm{eV}$. The high-resolution scans were conducted according to the peak being examined with a pass energy of $30 \mathrm{eV}$ and step size of $0.1 \mathrm{eV}$. All the binding energies were referenced to the $\mathrm{C} 1 s$ hydrocarbon peak at $284.8 \mathrm{eV}$.

The particle size of PDA/CMC complex was measured by Marvin laser granulometer (Zetasizer Nano ZS90, UK).

The surface morphology was studied using a scanning electron microscopy (JEOL, JSM-5600V, Japan) with $10 \mathrm{kV}$ acceleration voltages. Before observation, the hydrogels was freeze-dried. Then, the sample was sprayed by galvanic platinum deposition with a current of $5 \mathrm{~mA}$ for $90 \mathrm{~s}$ for enhancement of conductivity before measurements. The elemental analysis and mapping of PDA/CMC/PAA hydrogels were performed using an energy-dispersive X-ray spectrometer (EDS) with an $150 \mathrm{~mm}^{2}$ SDD detector (Oxford Instruments X-MaxN, USA) at $10 \mathrm{kV}$ acceleration voltages.

The dynamic rheological behavior of the PAA and PDA/CMC/PAA hydrogels was characterized using a stress-controlled rheometer Rotational Rheometer MARS III Haake (MARS III, Germany) at room temperature. The diameter of parallel plate geometry was $35 \mathrm{~mm}$. The hydrogels were loaded into a $1.0 \mathrm{~mm}$ gap between the plates. During strain scanning test, the samples deformed under different shear strains. The storage modulus $\left(\mathrm{G}^{\prime}\right)$ and loss modulus $\left(\mathrm{G}^{\prime \prime}\right)$ were measured by frequency sweeps at angular velocities ranging from 0.1 to $100 \mathrm{~Hz}$.

Swelling ratios of the hydrogels in ultrapure water were measured at room temperature. The freeze-dried hydrogels were weighed to record the initial weight $\left(W_{0}\right)$. Then, the weight $\left(W_{\mathrm{t}}\right)$ of the hydrogels was recorded at a series of time interval until reaching the equilibrium state. The swelling ratio of hydrogels was calculated using the following formula (Jing et al. 2018):

Swelling ratio $(\%)=\left[\left(W_{\mathrm{t}}-W_{0}\right) / W_{0}\right] \times 100 \%$ 


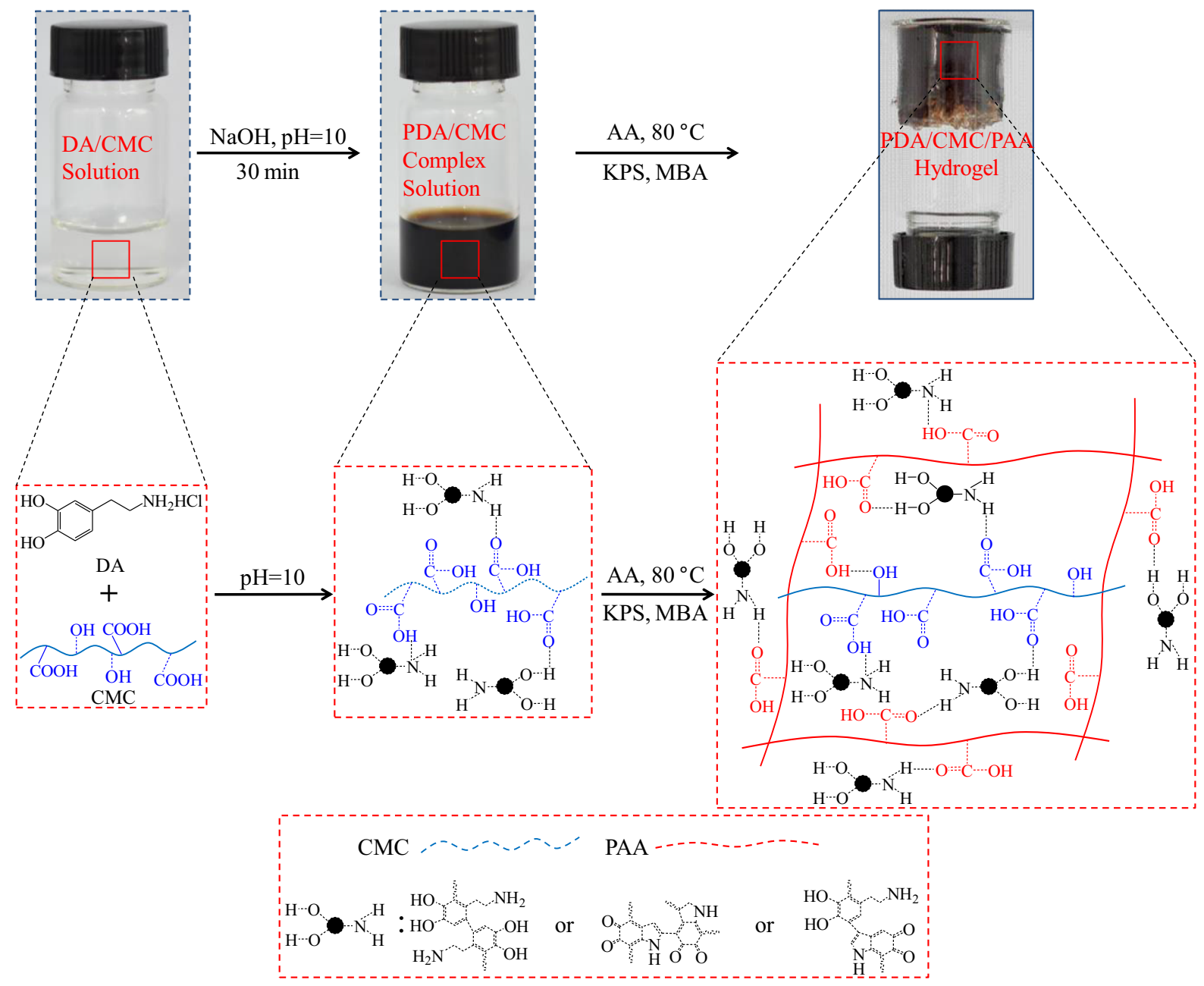

Fig. 1 Schematic of the formation of mussel-inspired PDA/CMC/PAA hydrogel

\section{Adhesion test}

The adhesion strength of the hydrogels on stainless steel, aluminum, glass and porcine skin was evaluated using a universal mechanical testing machine (KJ1065B, China). The hydrogels were cut into sheets with thickness of $1 \mathrm{~mm}$ and loaded on the substrates. Two substrates were overlapped to form single lap joint configurations with adhered size of $1.5 \mathrm{~cm} \times$ $1.2 \mathrm{~cm}$. Then, $20 \mathrm{~N}$ of force was applied to the bonding area of the substrates, which was maintained for 3 days at room temperature. Finally, the adhesion strength was tested. The tests were repeated with three parallel specimens. The adhesion strength of hydrogels was calculated using the following formula (White and Wilker 2011):
$\tau=F_{\max } / S$

where $\tau$ is the bonding strength (Pa); $F_{\max }$ is bonding tension at the break point $(\mathrm{N})$; and $S$ is the area of the overlapped adherend $\left(\mathrm{m}^{2}\right)$.

Mechanical testing

The compression tests of the PAA and PDA/CMC/ PAA hydrogels were carried out using a universal mechanical testing machine (KJ-1065B, China). The cylinder hydrogels with diameter of $24 \mathrm{~mm}$ and height of $12 \mathrm{~mm}$ were prepared for the compression test. During the compression, the speed of cross-head was $1 \mathrm{~mm} / \mathrm{s}$. The compression strength was defined as stress when the compressive strain reached $80 \%$ (Han et al. 2018a, b). The compression resilience of the 
PDA/CMC/PAA hydrogels was characterized by four cyclic loading-unloading compression tests to a compression strain of $80 \%$ after every $30 \mathrm{~min}$ of recovery of the hydrogels. Each compression test was repeated three times. The compression strain $(\varepsilon)$ and stress $(\sigma)$ of hydrogels were calculated using the following formula (Han et al. 2018a, b):

$\varepsilon=h / h_{0}$

$\sigma=F / S$

where $h$ is the deformed height and $h_{0}$ is the initial height, $F$ is the compressive load and $S$ is the original area of the sample.

\section{Biocompatibility evaluations}

NIH 3T3 cells were cultured in DMEM medium, which contains $10 \% \mathrm{FBS}$ and 10 units/mL penicillinstreptomycin at $37{ }^{\circ} \mathrm{C}$ and $5 \% \mathrm{CO}_{2}$ in a saturated humidity incubator. The hydrogels were cut into small rectangular blocks $(1 \times 1 \times 2 \mathrm{~mm})$, which were immersed in deionized water for 3 days, and the deionized water was replaced every $6 \mathrm{~h}$. The hydrogels were washed with PBS and sterilized under ultraviolet for $30 \mathrm{~min}$. After sterilization, the samples were placed in a 96-well plate, and cells were seeded on the hydrogels at a density of $3 \times 10^{3}$ cells/well. After being cultured for $24 \mathrm{~h}$ and $120 \mathrm{~h}$, the cell viability was measured using MTT assay. For this purpose, $20 \mu \mathrm{L}$ of MTT $(5.0 \mathrm{mg} / \mathrm{mL})$ was added into each well and the cells were incubated for $4 \mathrm{~h}$ at $37{ }^{\circ} \mathrm{C}$. The supernatant was sucked after centrifugation. The supernatant was mixed uniformly by adding $150 \mu \mathrm{L} /$ well of DMSO. OD (optical density) values at $490 \mathrm{~nm}$ were then measured using a microplate reader (Infinite F50, TECAN). The morphology of the cells was observed by a fluorescence microscopy (CX4172C02, Olympus) after the cells were stained by calcein AM/PI. The relative cell viability was calculated by the following equation ( $\mathrm{Li}$ et al. 2016; Zhao et al. 2020):

$$
\begin{aligned}
& \text { Relative cell viability }(\%) \\
& \quad=A_{\text {Hydrogel }} / A_{\text {Control }} \times 100 \%
\end{aligned}
$$

where $A_{\text {Hydrogel }}$ and $A_{\text {Control }}$ are the absorbance for cells cultured in the hydrogel piece and in cell culture medium, respectively. For each hydrogel formulation, three independent cultures were prepared and cytotoxicity test was repeated three times.

In vivo demonstration of the UV-resistant hydrogels

Three mice (6-8 weeks, weighing 50-100 g) were used for animal experiment. The mice were anaesthetized with pentobarbital ( 2 wt. $\%, 2 \mathrm{~mL} / \mathrm{kg}$ ). The dorsal skin surface was shaved and cleaned before test. Then the dorsal skin was irradiated by UV light $\left(30 \mathrm{~mW} / \mathrm{cm}^{2}, 365 \mathrm{~nm}\right.$ ) for $20 \mathrm{~min}$ (Han et al. 2018a, b) with different treatments: (1) the naked skin was not protected without hydrogel, (2) the skin was covered by PAA hydrogel, (3) the skin was covered by the PDA/CMC/PAA hydrogel. After UV irradiation, the animals sacrificed and the irradiated skin was collected and fixed in $10 \%$ formalin. The skin surface tissue was cut into slices vertically for cross-sectional observation. Histological observations were performed using optical microscopy (EVOS M5000, USA) after hematoxylin-eosin (H\&E staining) and Masson staining. All animal procedures were performed in accordance with the protocols approved by animal experiment ethics committee of Fujian Agriculture and Forestry University, as well as the local ethics committee and laboratory animal administration rules of China.

\section{Results and discussion}

Formation of the PDA/CMC/PAA hydrogel

The formation of multifunctional PDA/CMC/PAA hydrogel is shown in Fig. 1. Firstly, after dissolving DA in CMC solution, the amino groups and catechol groups in DA interacted with the carboxyl groups in CMC through hydrogen bonding. DA was deposited on the surface of water-soluble CMC chains. Under basic condition, DA was self-polymerized to form PDA/CMC complex and the solution turned black. PDA/CMC particles were dispersed well in the solution. Secondly, AA monomers were polymerized in the PDA/CMC solution to form covalently cross- 
linked PAA network, generating PDA/CMC/PAA adhesive hydrogel. Because $\mathrm{CMC}$ and $\mathrm{AA}$ have a large number of carboxyl groups and PDA has large amounts of phenolic hydroxyl and amino groups, the hydrogen bonding was also formed among PDA, $\mathrm{CMC}$, and PAA. This provides a simple and effective approach to incorporate PDA nanoparticles into polymeric matrix to fabricate PDA/CMC/PAA hydrogels, which could avoid complicated chemical reaction (Guvendiren et al. 2008). Furthermore, the hydrogels were enriched with catechol groups, providing the hydrogels with cell affinity and tissue adhesiveness for cell attachment, spreading, proliferation and UV-shielding performance.

\section{Properties characterization of hydrogels}

XPS spectra of the hydrogels are shown in Fig. 2. The spectrum of PAA hydrogel in Fig. 2A,a only showed $\mathrm{O} 1 s$ and $\mathrm{C} 1 s$ peaks, near $533.1 \mathrm{eV}$ and $285.1 \mathrm{eV}$. A new peak at $400.1 \mathrm{eV}$ (Lu et al. 2018), N $1 s$, appeared in the spectrum of $\mathrm{PDA} / \mathrm{CMC} / \mathrm{PAA}$ hydrogel (Fig. 2A,b), indicating PDA/CMC/PAA hydrogel contains DA. In the narrow scan of $\mathrm{C} 1 s$ spectra, the peaks of PAA hydrogel at $288.6 \mathrm{eV}, 286.5 \mathrm{eV}$ and $284.8 \mathrm{eV}$ (Fig. 2B,a) were attributed to the bonds of $\mathrm{O}-\mathrm{C}=\mathrm{O}, \mathrm{C}-\mathrm{O}$ and $\mathrm{C}-\mathrm{C}$, respectively (Jing et al. 2018). The peaks of PDA/CMC/PAA hydrogel in Fig. 2B,b at $288.5 \mathrm{eV}, 286.4 \mathrm{eV}$ and $284.8 \mathrm{eV}$ are mainly ascribed to the bonds of $\mathrm{O}-\mathrm{C}=\mathrm{O}, \mathrm{C}-\mathrm{O} / \mathrm{C}-\mathrm{N}$ and $\mathrm{C}-$ $\mathrm{C}$, respectively (Guo et al. 2019). The intensity of peak at $286.4 \mathrm{eV}$ in Fig. 2B,b is stronger than that in Fig. 2B,a, showing that the content of $\mathrm{C}-\mathrm{N}$ species in PDA/CMC/PAA hydrogel is higher than that in PAA hydrogel.

FTIR spectra of pure PAA hydrogel and PDA/ CMC/PAA hydrogel were presented in Fig. $2 \mathrm{C}$. The broad and strong absorption band at $3420 \mathrm{~cm}^{-1}$ in PAA hydrogel is attributed to the symmetrical stretching vibration of $\mathrm{O}-\mathrm{H}$ stretching peak of PAA (Shao et al. 2017). The characteristic stretching vibrations of $\mathrm{CH}_{2}$ and $\mathrm{C}=\mathrm{O}$ are located at $2940 \mathrm{~cm}^{-1}$ and $1720 \mathrm{~cm}^{-1}$, respectively. In the FTIR spectra of PDA/CMC/PAA hydrogel (Fig. 2C,b), the absorption band at $1160 \mathrm{~cm}^{-1}$ arises from the asymmetric stretching of glycosidic bridge $\mathrm{C}-\mathrm{O}-\mathrm{C}$ (Guo et al. 2019), indicating CMC was incorporated into PDA/CMC/PAA hydrogel.
In the UV-Vis spectra (Fig. 2D), the UV absorbances of PDA/CMC/PAA hydrogels in the range of 200-600 nm were much higher than that of PAA hydrogel, showing that PDA/CMC/PAA hydrogels had remarkable UV shielding performance. The UV absorbance of the PDA/CMC/PAA hydrogel increased with increasing the PDA content. This result was attributed to the functional phenolic groups in PDA for UV absorption. To examine the influence of aging and UV degradation on the UV shielding performance of the gel, the intensity of UV absorbance of $\mathrm{PDA}_{0.02} / \mathrm{CMC} / \mathrm{PAA}$ hydrogel under normal condition and ultraviolet radiation (wavelength, $365 \mathrm{~nm}$; power, $4 \mathrm{~W} / \mathrm{m}^{2}$ ) at different time were monitored. Under normal condition (Fig. 2E), it can be seen that almost no obvious changes of UV absorbance can be observed over time. Thus, aging almost has no influence on the UV shielding of PDA/CMC/PAA hydrogel. Under exposure to ultraviolet radiation (Fig. 2F), the UV absorption had little decrease 4 weeks later. However, this decrease was not sufficient to change the UV shielding performance of PDA/ CMC/PAA hydrogels. Therefore, the PDA/CMC/ PAA hydrogels can be used for long-term UVresistant materials.

Because the $\mathrm{PDA}_{0.02} / \mathrm{CMC} / \mathrm{PAA}$ hydrogel has good UV shielding performance, $\mathrm{PDA}_{0.02} / \mathrm{CMC} / \mathrm{PAA}$ hydrogel was used as an example to observe the microstructure of PDA/CMC/PAA hydrogel by scanning electron microscopy (SEM) after the hydrogels were freeze-dried. As shown in Fig. 3a, the PAA hydrogel presented large holes with smooth surfaces. After addition of PDA/CMC complex, the PDA/CMC/ PAA hydrogel exhibited interconnected irregular porous and loose structure (Fig. 3b). The complicated meshwork mimicked the structural diversity of the extracellular matrix (Wang et al. 2016a, b, c). The mapping of $N$ element in PDA/CMC/PAA hydrogel was measured using EDS, which was shown as the red dots (Fig. 3b). Because only the PDA component contains $N$ element, the location of $N$ element showed the distribution of PDA in hydrogel. It can be observed that PDA/CMC complex were distributed on PDA/ CMC/PAA hydrogel homogeneously. The size of the PDA/CMC nanoparticles measured by a Marvin laser granulometer was $100 \pm 10 \mathrm{~nm}$ with polydispersity of 0.82 (Inset in Fig. 3b). The well dispersion of PDA/ $\mathrm{CMC}$ nanoparticles in PDA/CMC/PAA hydrogel is in favor of the production of UV-shielding hydrogels. 
Fig. 2 XPS spectra of A survey scan, B C 1 s scan, and C FTIR spectra of (a) PAA hydrogel and (b) $\mathrm{PDA}_{0.02} / \mathrm{CMC} / \mathrm{PAA}$ hydrogel. D UV-Vis absorption spectra of (a) PAA hydrogel, (b) $\mathrm{PDA}_{0.01} / \mathrm{CMC} / \mathrm{PAA}$ hydrogel, (c) $\mathrm{PDA}_{0.02} / \mathrm{CMC} /$ PAA hydrogel, (d) $\mathrm{PDA}_{0.04} /$ CMC/PAA hydrogel, and (e) $\mathrm{PDA}_{0.08} / \mathrm{CMC} / \mathrm{PAA}$ hydrogel. UV-Vis absorption spectra of $\mathrm{PDA}_{0.02} / \mathrm{CMC} / \mathrm{PAA}$ hydrogel under $\mathbf{E}$ normal condition and $\mathbf{F}$ ultraviolet radiation at different time
(A)

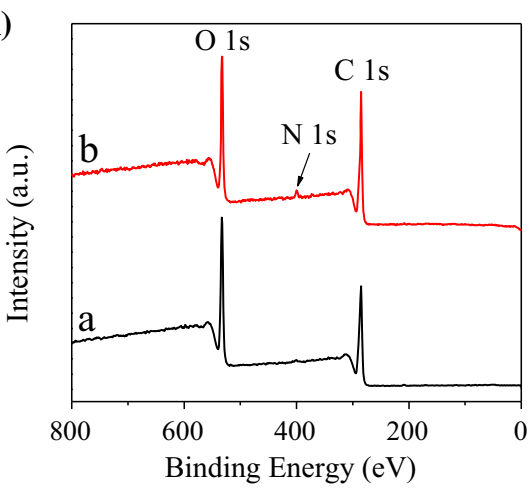

(C)

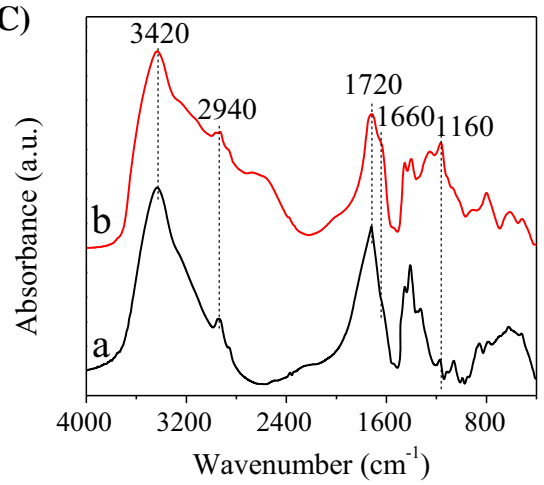

(E)

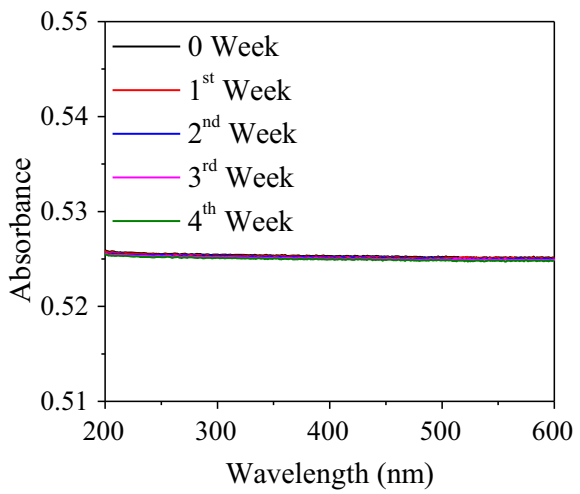

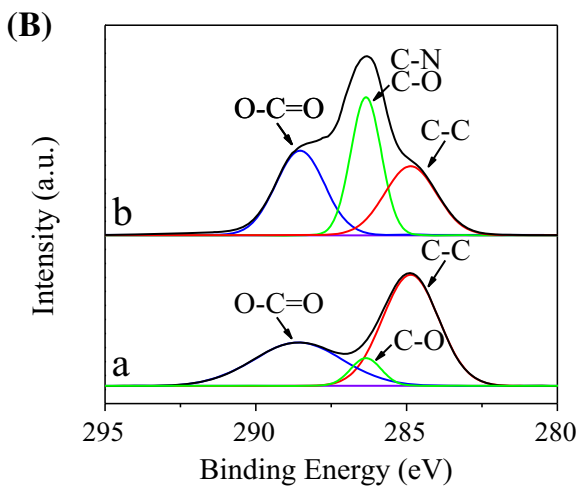

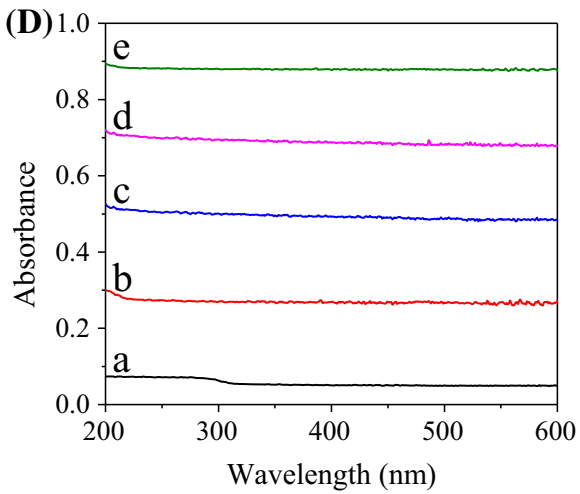

(F)

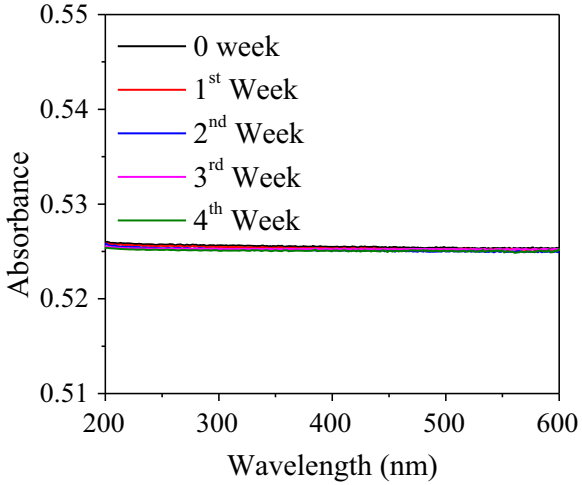

To investigate the rheological behavior of the hydrogels, the storage modulus $\left(\mathrm{G}^{\prime}\right)$ and loss modulus $\left(\mathrm{G}^{\prime \prime}\right)$ of hydrogels were monitored. The rheology data are shown in Fig. $3 \mathrm{c}$. For the $\mathrm{PDA}_{0.02} / \mathrm{CMC} / \mathrm{PAA}$ hydrogel, $G^{\prime}$ value was higher than $G^{\prime \prime}$ value, indicating a gel network with elastic behavior rather than viscous nature. The $\mathrm{G}^{\prime}$ curves of all the hydrogels exhibited the plateau-like behavior, indicating the rubbery plateau region of the hydrogels network. This could be ascribed to the crosslinking structure generated by PDA, CMC and PAA. The $\mathrm{G}^{\prime}$ and $\mathrm{G}^{\prime \prime}$ value of
$\mathrm{PDA}_{0.02} / \mathrm{CMC} / \mathrm{PAA}$ hydrogel were lower than those of PAA hydrogel in the whole frequency range. This could be caused by the hydrogen bonding interaction between the PDA/CMC complex and PAA, which enhanced the viscoelastic property of the hydrogel.

Figure $3 \mathrm{~d}$ shows variation of the swelling ratio of $\mathrm{PDA}_{0.02} / \mathrm{CMC} / \mathrm{PAA}$ and PAA hydrogels in water over time. The swelling ratio of $\mathrm{PDA}_{0.02} / \mathrm{CMC} / \mathrm{PAA}$ and PAA hydrogels gradually increased with time. When the hydrogels were soaked in water for 3 days, the dynamic equilibrium reached, and the swelling ratio of 
Fig. 3 SEM images of the internal microstructure of a PAA hydrogel and b $\mathrm{PDA}_{0.02} / \mathrm{CMC} / \mathrm{PAA}$ hydrogel. EDS mapping analysis of $N$ element is shown in $\mathbf{b}$ and the red dots show the distribution of PDA in hydrogel. Inset in b is average particle size of PDA/CMC complex. c Storage modulus $\left(\mathrm{G}^{\prime}\right)$ and loss modulus $\left(\mathrm{G}^{\prime \prime}\right)$ of PAA hydrogel and $\mathrm{PDA}_{0.02} /$ CMC/PAA hydrogel; d Swelling ratio of PAA hydrogel and $\mathrm{PDA}_{0.02} /$ CMC/PAA hydrogel (a)

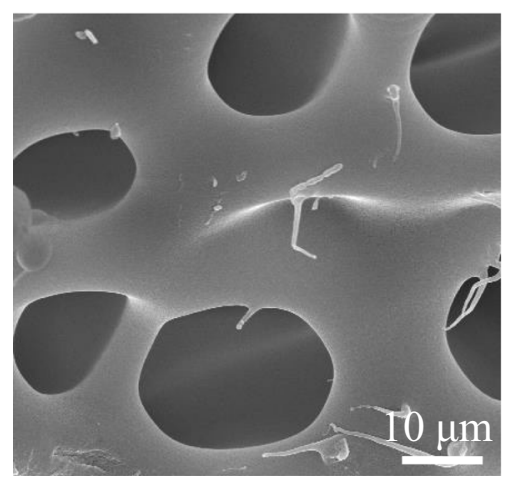

(c)

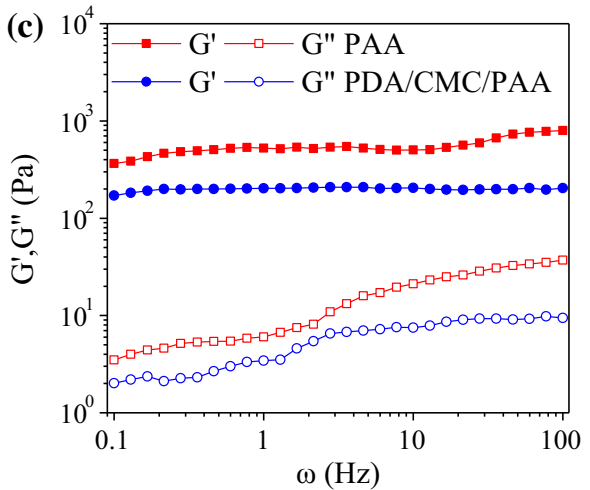

(b)
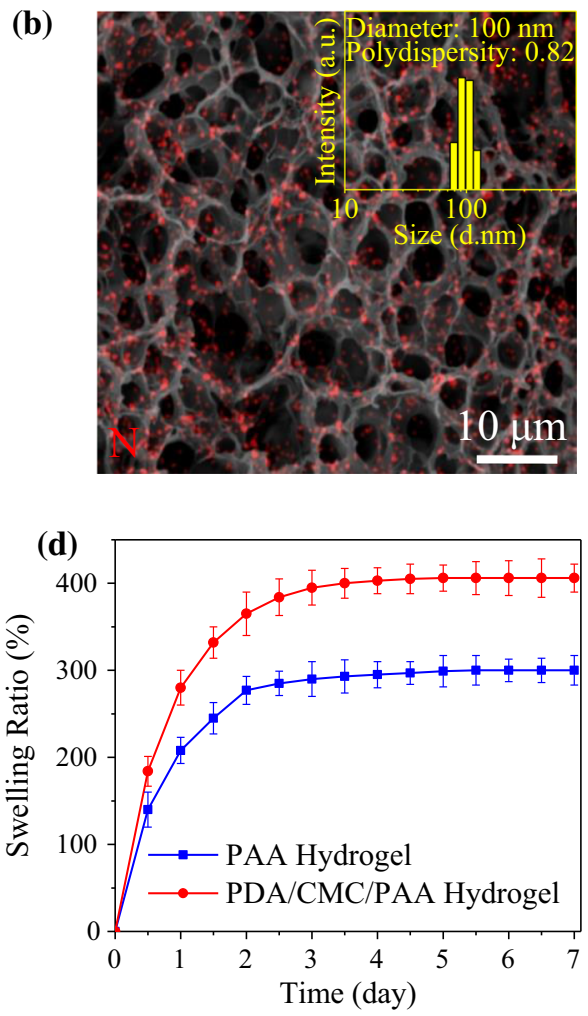

$\mathrm{PDA}_{0.02} / \mathrm{CMC} / \mathrm{PAA}$ and PAA hydrogels was $406 \%$ and $300 \%$, respectively. Compared with the pure PAA hydrogel, $\mathrm{PDA}_{0.02} / \mathrm{CMC} / \mathrm{PAA}$ hydrogel had a $106 \%$ higher swelling ratio. The swelling ratio of hydrogels is closely related to the morphology, the number of pores, the number of hydrogen bonds and crosslinking density of hydrogel. The addition of PDA/CMC complex introduced a large number of hydrophilic groups into the hydrogel, and the PAA molecular chain contained a large number of carboxyl groups, which could form hydrogen bonds with water and absorb a large amount of water to increase the swelling ratio.

\section{Adhesion strength}

Because adhesiveness to skin surfaces is an important property to hydrogels, the adhesion strength was tested. $\mathrm{PDA}_{0.02} / \mathrm{CMC} / \mathrm{PAA}$ hydrogel could stick to a dry finger, and the hydrogel would not fall off (Fig. 4a), visually showing that hydrogel had good adhesive property. Meanwhile, PDA/CMC/PAA hydrogel could also stick to the sweaty finger (Fig. 4b), indicating that the hydrogel still has good adhesion after sweating. The adhesion strength of the PAA hydrogel on the stainless steel, aluminum, glass and porcine skin was measured to be $560 \pm 50 \mathrm{kPa}$, $260 \pm 40 \mathrm{kPa}, \quad 135 \pm 15 \mathrm{kPa}$ and $12 \pm 2 \mathrm{kPa}$, respectively (Fig. 4c). However, when the PDA/ CMC/PAA hydrogels were applied on the stainless steel, aluminum, glass, and porcine skin, the adhesion strength was $780 \pm 50 \mathrm{kPa}, \quad 350 \pm 40 \mathrm{kPa}$, $200 \pm 25 \mathrm{kPa}$, and $20 \pm 2 \mathrm{kPa}$ in a dry condition, respectively, which was significantly higher than that of the PAA hydrogel. The maximum adhesive strength was obtained by using stainless steel, which is hundreds of times stronger than that of porcine skin. The strong adhesion ability of hydrogel was attributed to the interaction of functional catechol groups with solid surface, including complexation and hydrogen bonding ( $\mathrm{Li}$ et al. 2015). Furthermore, the adhesion strength of PDA/CMC/PAA hydrogels with porcine skin was higher than that of the fibrin adhesive (ca. $12.0 \mathrm{kPa}$ ) (Zhang et al. 2014; Zhou et al. 2015). This indicated the catechol groups in hydrogel had high binding affinity to diverse nucleophiles (e.g., $-\mathrm{OH},-$ $\mathrm{NH}_{2}$ ) of peptides and proteins on tissue surfaces with hydrogen bonding (Gao et al. 2018). 
(a)
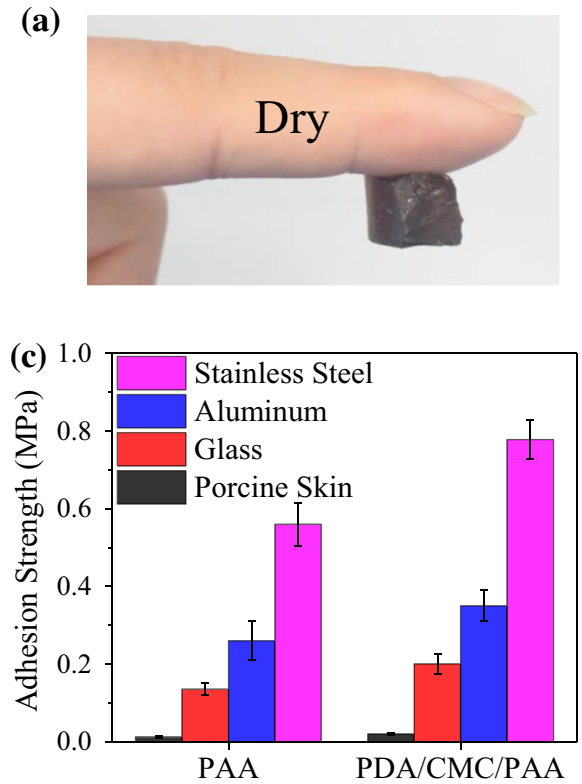

Fig. 4 Images of a $\mathrm{PDA}_{0.02} / \mathrm{CMC} / \mathrm{PAA}$ hydrogel sticking to a $\mathbf{a}$ dry finger and $\mathbf{b}$ sweaty finger. $\mathbf{c}$ Adhesive strength of PAA and $\mathrm{PDA}_{0.02} / \mathrm{CMC} / \mathrm{PAA}$ hydrogels on different substrates.

In order to further investigate the validity of hydrogels, the adhesive strength of hydrogels at different time was measured. As shown in Fig. 4d, the adhesion strength of the $\mathrm{PDA}_{0.02} / \mathrm{CMC} / \mathrm{PAA}$ hydrogel kept the value of ca. $20 \mathrm{kPa}$ after 4 weeks, although there are some negligible deviation. The results showed that the adhesion strength has no obvious change after a period of time and could still be used. Therefore, the PDA/CMC/PAA hydrogels can be applied as functional adhesive coating on the skin.

\section{Mechanical testing}

Because the PDA/CMC complex were introduced into the covalent crosslinked PAA network with noncovalent hydrogen bonding interactions for energy dissipation, the PDA/CMC/PAA hydrogels were resilient and tough. Under compressive loading, PAA hydrogel was crushed directly (Fig. 5a), showing that PAA hydrogel was quite brittle. However, PDA/ CMC/PAA hydrogel recovered to its original shape after the removal of the load, and no cracks could be observed in the hydrogel (Fig. 5b), indicating that the PDA/CMC/PAA hydrogels had excellent elasticity and toughness. Figure $5 \mathrm{c}$ shows the compression (b)
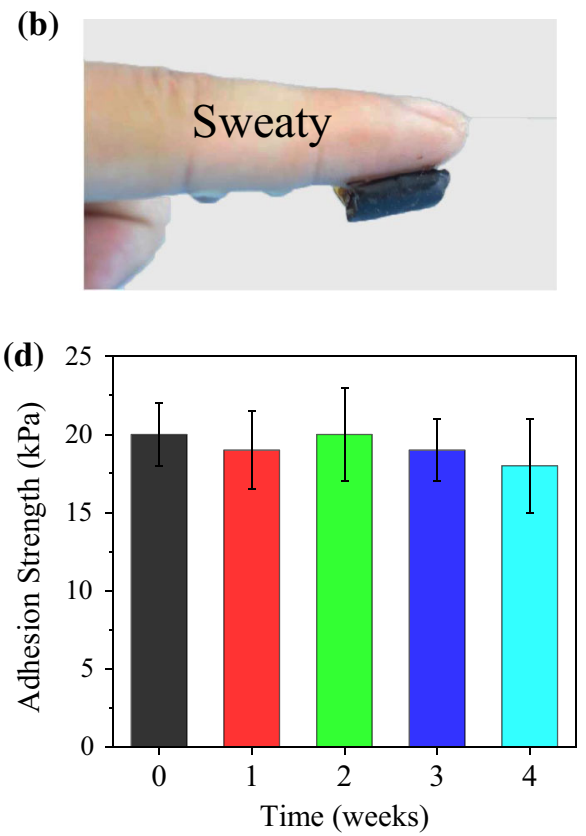

d Adhesive strength of $\mathrm{PDA}_{0.02} / \mathrm{CMC} / \mathrm{PAA}$ hydrogel on porcine skin at different time

stress-strain curves of the hydrogel. The compressive strength $(\sigma)$ of hydrogel was evaluated at compressive strain $(\varepsilon)$ of $80 \%$. The $\sigma$ of the pure PAA hydrogel was only $0.12 \pm 0.02 \mathrm{MPa}$. After the incorporation of $\mathrm{PDA} / \mathrm{CMC}$ complex, the $\sigma$ of the PDA/CMC/PAA hydrogel increased to $0.14 \pm 0.02 \mathrm{MPa}$. This is because the hydrogen bonding between carboxyl groups in CMC and PAA and amino groups in PDA could re-form during the compressive test, imparting that the PDA/CMC/PAA hydrogel had good resilience and high compressive strength to withstand large deformation. Cyclic compression testing showed that the PDA/CMC/PAA hydrogels had a hysteresis loop after the first loading up to $80 \%$ strain (Fig. 5d). Moreover, the curves of the recovered hydrogels were similar to that of the original one after four loadingunloading cycles, and the recovered hydrogels still maintained high compressive strength.

Biocompatibility evaluations

Biocompatibility is a critical requirement for directcontact skin and wearable devices. The cytotoxicity of synthesized hydrogels was investigated using NIH $3 \mathrm{~T} 3$ cells. The relative cell viability and morphology 
Fig. 5 a PAA hydrogel and b $\mathrm{PDA}_{0.02} / \mathrm{CMC} / \mathrm{PAA}$ hydrogel after $80 \%$ of compression; c typical compression stress-strain curves of PAA and $\mathrm{PDA}_{0.02}$ / CMC/PAA hydrogel; d cyclic compressive loading-unloading test of the $\mathrm{PDA}_{0.02} / \mathrm{CMC} / \mathrm{PAA}$ hydrogel
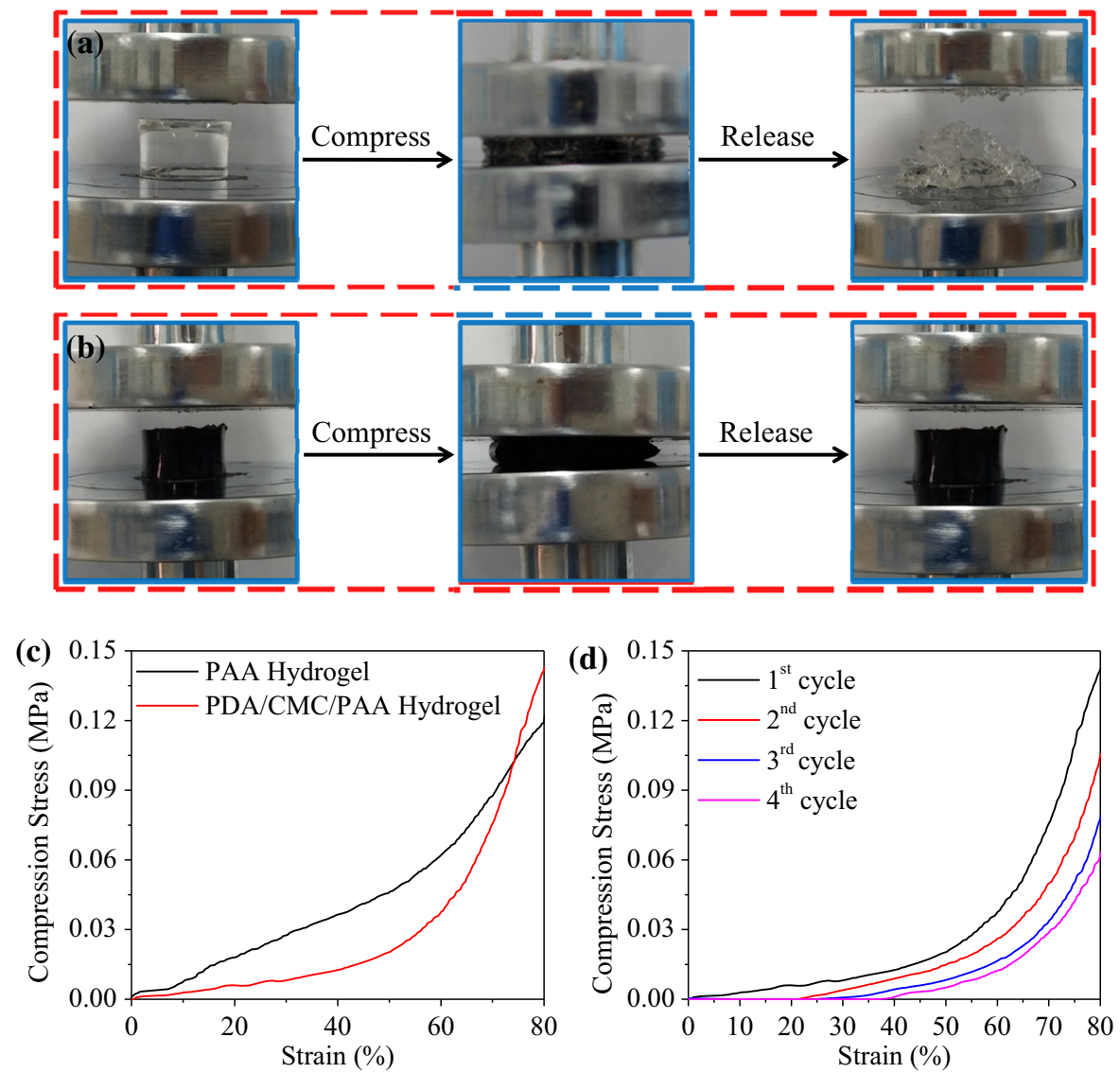

were investigated at 1 day and 5 days. To study the cell morphology, the cells were double-stained with calcein AM/PI. The live cells appeared green and the dead ones were red, as shown in Fig. 6. The cells cultured on the PDA/CMC/PAA hydrogel showed a spread morphology with clearly visible elongated filopodia. After 5 days of culture, the cell number increased significantly, demonstrating a flourishing living state on the hydrogels. The relative cell viability of the hydrogels was higher than $90 \%$ at these two time points, indicating the hydrogels had good biocompatibility (Liu et al. 2014). The better cell affinity on the hydrogel was mainly because the PDA benefits to serum absorption on surface of hydrogel, which is favorable for cell attachment and proliferation (Jing et al. 2018). Therefore, these results demonstrate that the PDA/CMC/PAA hydrogels possessed good biocompatibility and should be a safe candidate material for biomedical and wearable devices.
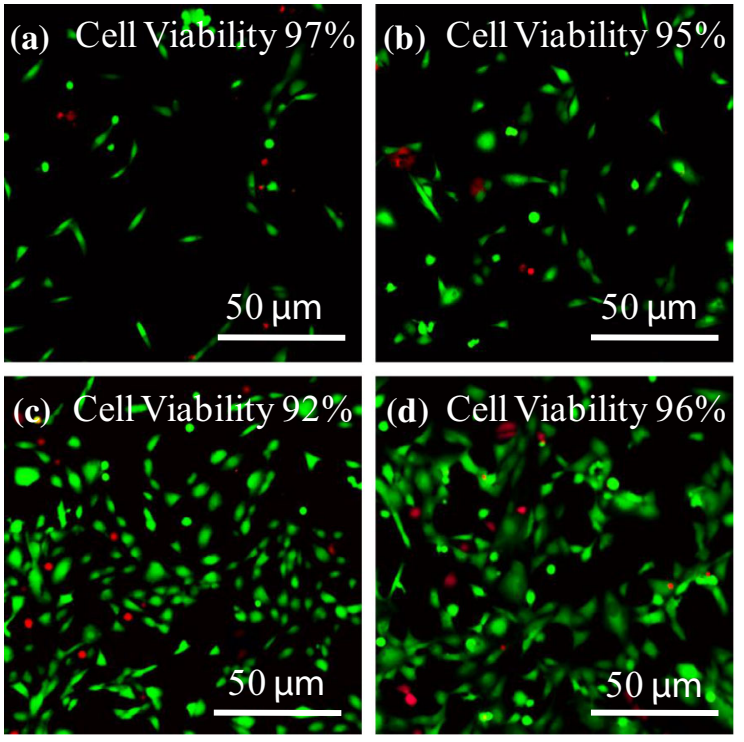

Fig. 6 Relative cell viability and live/dead images of cells cultured on a PAA hydrogel for 1 day; $\mathbf{b} \mathrm{PDA}_{0.02} / \mathrm{CMC} / \mathrm{PAA}$ hydrogel for 1 day; c PAA hydrogel for 5 days; and $\mathbf{d} \mathrm{PDA}_{0.02} /$ CMC/PAA hydrogel for 5 days 


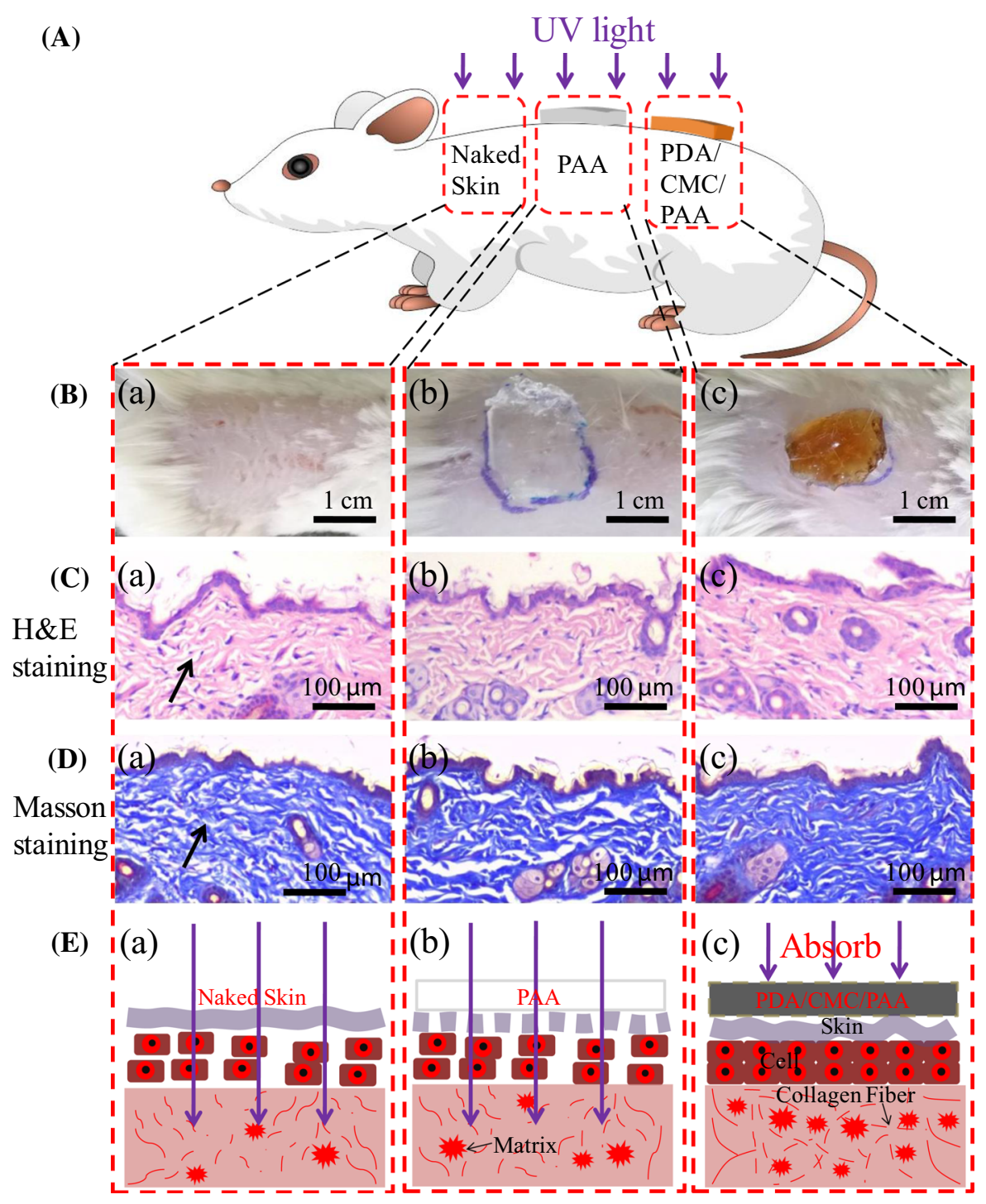

Fig. 7 A Schematic of dorsal skin of mouse covered by PAA and $\mathrm{PDA}_{0.02} / \mathrm{CMC} / \mathrm{PAA}$ hydrogels. B Photos of skin after 20 min of UV irradiation, histological micrographs of $\mathbf{C ~ H \& E}$

\section{UV-shielding performance of the PDA/CMC/PAA} hydrogels

UV ray can stimulate the skin keratinocytes, increase the amount of reactive oxygen species, causing damage to cells (Dey et al. 2015). It is reported that the relative cell viability was only $6 \%$ and most of cells were killed by UV radiation when the cells were exposed directly to UV ray (Wang et al. 2019a, b). It is important to protect skin to against UV radiation for the sake of health. staining and $\mathbf{D}$ Masson staining, and $\mathbf{E}$ schematic demonstration of UV-shielding of (a) naked skin, (b) PAA hydrogel-covered skin, and (c) PDA/CMC/PAA hydrogel-covered skin

In vivo animal experiment, the PAA and PDA/ CMC/PAA hydrogels were adhered on the back skin of a mouse, and then the mouse was irradiated to UV light, as illustrated in Fig. 7A. After UV irradiation, the photographs of the naked skin without protection (Fig. 7B,a), the skin covered by PAA hydrogel (Fig. 7B,b), and the skin covered by PDA/CMC/ PAA hydrogel (Fig. 7B,c) are shown in Fig. 7B. The UV-irradiated skins were sectioned and stained. The collagen fibers were dyed pink through H\&E staining and blue through Masson staining. As can be seen 


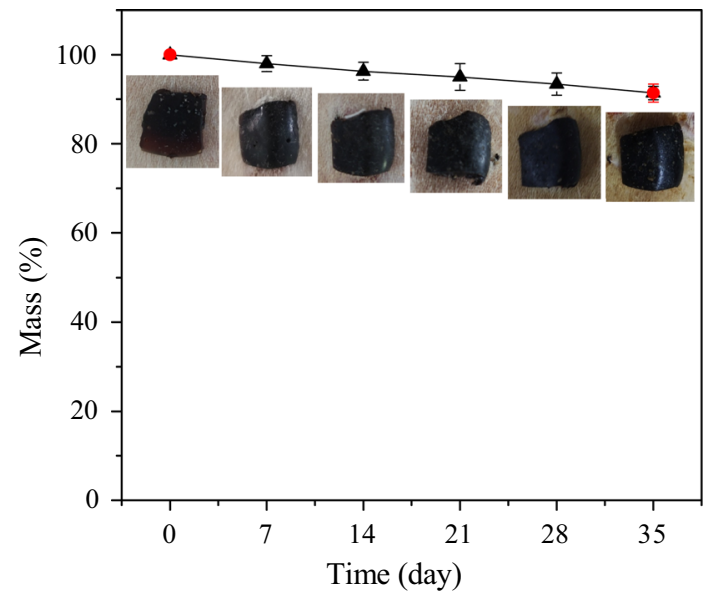

Fig. 8 Mass changes of $\mathrm{PDA}_{0.02} / \mathrm{CMC} / \mathrm{PAA}$ hydrogel on the naked skin of mouse (black triangle) and in the glass dish (red circle) over time. Inset is the images of the $\mathrm{PDA}_{0.02} / \mathrm{CMC} / \mathrm{PAA}$ hydrogel on the naked skin of mouse

from the Fig. 7, the collagen fibers of the skin, which were not covered by the hydrogel, had large white hollow (Fig. 7C,a, D,a). This result indicated the naked skin had a severe injury of collagen under UV irradiation (Han et al. 2018a, b). Similarly, severe injury of collagen was observed in the PAA hydrogelcovered skin (Fig. 7C,b, D,b), which confirmed that PAA hydrogel has little anti-UV effect. Compared with the naked skin and PAA hydrogel-covered skin, the collagen fibers of the skin protected by PDA/CMC/ PAA hydrogel had less white hollow area, and the alignment of collagen was well preserved (Fig. 7C,c, $\mathrm{D}, \mathrm{c})$. The schematic demonstration of the hydrogel used as a skin coating for UV-shielding was shown in Fig. 7E. When the skin was covered without hydrogel or with PAA hydrogel, UV irradiation resulted in irregular alignment of cells and destruction of collagen fibers (Fig. 7E,a, E,b). However, for the skin covered with PDA/CMC/PAA hydrogel, the cells were roughly aligned and the collagen fibers remained intact (Fig. 7E,c). Because PDA nanoparticles can convert the photon energy of UV light into heat rapidly (Wang et al. 2017), the UV light could be captured and absorbed by the PDA nanoparticles in PDA/CMC/ PAA hydrogel during the UV irradiation. These results indicated that the PDA/CMC/PAA hydrogels had good UV-shielding property and were able to protect skin from UV irradiation.

To test whether the hydrogel was adsorbed by epidermal cells, the hydrogels were cut into cuboids
$(11.2 \times 10.7 \times 3.0 \mathrm{~mm})$ to cover the naked skin of mouse, and the hydrogels were contacted with the epidermal cells closely under relative humidity of $52.5 \%$ at $25.5{ }^{\circ} \mathrm{C}$. The weight of the hydrogel was recorded and photographed every week. As can be seen from Fig. 8, the hydrogels were stable and no obvious morphology changes can be observed over 35 days. The mass of hydrogel slightly decreased over time, which is the same as the control hydrogel in the glass dish. The decrease in mass might be attributed to the water lost. Thus, it is hard to detect the morphology and weight difference between the hydrogel on the naked skin of mouse and the hydrogel in the glass dish. Therefore, the hydrogel is almost not absorbed by the epidermal cells. This indicates that PDA/CMC/PAA hydrogels have great potential for the applications in skin care products.

\section{Conclusions}

In summary, UV-resistant PDA/CMC/PAA hydrogels were developed by introducing PDA/CMC complex into an polymer network, which harnessed the advantages of adhesiveness of PDA for promoting cell adhesion and excellent UV-resistant performance. By forming the PDA/CMC complex, PDA was well dispersed in PAA matrix to form PDA/CMC/PAA hydrogel. The hydrogen bonding interaction between the CMC/PDA complex and PAA imparted the PDA/ CMC/PAA hydrogels good resilience and high compressive strength to withstand large deformation. The hydrogels exhibited high adhesion to various surfaces of stainless steel, aluminum, glass and porcine skin. The good biocompatibility and UV-shielding ability make PDA/CMC/PAA hydrogels a promising candidate in the applications for UV filtration membrane and skin care products.

Acknowledgments This work was supported by the National Key R\&D Program of China (2018YFD06003023), the National Natural Science Foundation of China (21774021), the Award Program for Minjiang Scholar Professorship (KXNAD002A), and International Science and Technology Cooperation and Exchange Project of Fujian Agriculture and Forestry University (KXb16002A).

\section{Compliance with ethical standards}

Conflict of interest The authors declare that they have no conflict of interest. 


\section{References}

Abdelraheem WHM, He X, Duan X, Dionysiou DD (2015) Degradation and mineralization of organic UV absorber compound 2-phenylbenzimidazole-5-sulfonic acid (PBSA) using UV-254nm/ $/ \mathrm{H}_{2} \mathrm{O}_{2}$. J Hazard Mater 282:233-240

Baker LA, Marchetti B, Karsili TNV, Stavros VG, Ashfold MNR (2017) Photoprotection: extending lessons learned from studying natural sunscreens to the design of artificial sunscreen constituents. Chem Soc Rev 46:3770-3791

Cheng W, Zeng X, Chen H, Li Z, Zeng W, Mei L, Zhao Y (2019) Versatile polydopamine platforms: synthesis and promising applications for surface modification and advanced nanomedicine. ACS Nano 13:8537-8565

Corbyn Z (2014) Lessons from a sunburnt country. Nature 515:S114-S116

Cui K, Yan B, Xie Y, Qian H, Wang X, Huang Q, He Y, Jin S, Zeng H (2018) Regenerable urchin-like $\mathrm{Fe}_{3} \mathrm{O}_{4} @$ PDA-Ag hollow microspheres as catalyst and adsorbent for enhanced removal of organic dyes. J Hazard Mater 350:66-75

Dey A, Bera R, Ahmed S, Chakrabarty D (2015) Smart superabsorbent UV resistant etherified PVA gel: synthesis and characterization. J Ind Eng Chem 21:1219-1230

Dickerson RR, Kondragunta S, Stenchikov G, Civerolo KL, Doddridge BG, Holben BN (1997) The impact of aerosols on solar ultraviolet radiation and photochemical smog. Science 278:827-830

Faure E, Falentin-Daudre C, Jerome C, Lyskawa J, Fournier D, Woisel P, Detrembleur C (2013) Catechols as versatile platforms in polymer chemistry. Prog Polym Sci 38:236-270

Gao Z, Duan L, Yang Y, Hu W, Gao G (2018) Mussel-inspired tough hydrogels with self-repairing and tissue adhesion. Appl Surf Sci 427:74-82

Grządka E, Matusiak J, Bastrzyk A, Polowczyk I (2020) CMC as a stabiliser of metal oxide suspensions. Cellulose 27:2225-2236

Guo T, Gu L, Zhang Y, Chen H, Jiang B, Zhao H, Jin Y, Xiao H (2019) Bioinspired self-assembled films of carboxymethyl cellulose-dopamine/montmorillonite. J Mater Chem A 7:14033-14041

Guvendiren M, Messersmith PB, Shull KR (2008) Self-assembly and adhesion of DOPA-modified methacrylic triblock hydrogels. Biomacromol 9:122-128

Han L, Wang M, Li P, Gan D, Yan L, Xu J, Wang K, Fang L, Chan CW, Zhang H, Yuan H, Lu X (2018) Mussel-inspired tissue-adhesive hydrogel based on the polydopaminechondroitin sulfate complex for growth-factor-free cartilage regeneration. ACS Appl Mater Interfaces 10:28015-28026

Han L, Yan L, Wang M, Wang K, Fang L, Zhou J, Fang J, Ren F, Lu X (2018) Transparent, adhesive, and conductive hydrogel for soft bioelectronics based on light-transmitting polydopamine-doped polypyrrole nanofibrils. Chem Mater 30:5561-5572

Hayden CGJ, Cross SE, Anderson C, Saunders NA, Roberts MS (2005) Sunscreen penetration of human skin and related keratinocyte toxicity after topical application. Skin Pharmacol Phys 18:170-174
Heinze T, Pfeiffer K (1999) Studies on the synthesis and characterization of carboxymethylcellulose. Die Angew Makromol Chem 266:37-45

Hoffman AS (2012) Hydrogels for biomedical applications. Adv Drug Deliver Rev 64:18-23

Ikechukwu Ugwoke M, Kaufmann G, Verbeke N, Kinget R (2000) Intranasal bioavailability of apomorphine from carboxymethylcellulose-based drug delivery systems. Int J Pharm 202:125-131

Jing X, Mi H-Y, Peng X-F, Turng L-S (2018) Biocompatible, self-healing, highly stretchable polyacrylic acid/reduced graphene oxide nanocomposite hydrogel sensors via mussel-inspired chemistry. Carbon 136:63-72

Ju K-Y, Lee Y, Lee S, Park SB, Lee J-K (2011) Bioinspired polymerization of dopamine to generate melanin-like nanoparticles having an excellent free-radical-scavenging property. Biomacromol 12:625-632

Kirk RE, Othmer DF (1967) Cellulose encylopedia of chemical technology. New York: Wiley 4:593-683

Klemm D, Heublein B, Fink H-P, Bohn A (2005) Cellulose: fascinating biopolymer and sustainable raw material. Angew Chem Int Ed 44:3358-3393

Lee KY, Mooney DJ (2001) Hydrogels for tissue engineering. Chem Rev 101:1869-1880

Lee H, Dellatore SM, Miller WM, Messersmith PB (2007) Mussel-inspired surface chemistry for multifunctional coatings. Science 318:426-430

Li L, Smitthipong W, Zeng H (2015) Mussel-inspired hydrogels for biomedical and environmental applications. Polym Chem 6:353-358

Li Y, Meng H, Liu Y, Narkar A, Lee BP (2016) Gelatin microgel incorporated poly(ethylene glycol)-based bioadhesive with enhanced adhesive property and bioactivity. ACS Appl Mater Interfaces 8:11980-11989

Liu Y, Meng H, Konst S, Sarmiento R, Rajachar R, Lee BP (2014) Injectable dopamine-modified poly(ethylene glycol) nanocomposite hydrogel with enhanced adhesive property and bioactivity. ACS Appl Mater Interfaces 6:16982-16992

Liu Z, Hu J, Sun Q, Chen L, Feng X, Zhao Y (2017) Musselinspired multifunctional coating for enhancing the UVresistant property of polypropylene fibers. Macromol Res 25:431-438

Lu S, Tang Z, Li W, Ouyang X, Cao S, Chen L, Huang L, Wu H, Ni Y (2018) Diallyl dimethyl ammonium chloride-grafted cellulose filter membrane via ATRP for selective removal of anionic dye. Cellulose 25:7261-7275

Noonan FP, Recio JA, Takayama H, Duray P, Anver MR, Rush WL, De Fabo EC, Merlino G (2001) Neonatal sunburn and melanoma in mice. Nature 413:271-272

Pan Z, Lee W, Slutsky L, Clark RAF, Pernodet N, Rafailovich MH (2009) Adverse effects of titanium dioxide nanoparticles on human dermal fibroblasts and how to protect cells. Small 5:511-520

Patil N, Jerome C, Detrembleur C (2018) Recent advances in the synthesis of catechol-derived (bio)polymers for applications in energy storage and environment. Prog Polym Sci 82:34-91

Shao C, Chang H, Wang M, Xu F, Yang J (2017) High-strength, tough, and self-healing nanocomposite physical hydrogels based on the synergistic effects of dynamic hydrogen bond 
and dual coordination bonds. ACS Appl Mater Interfaces 9:28305-28318

Shen J, Song Z, Qian X, Yang F (2010) Carboxymethyl cellulose/alum modified precipitated calcium carbonate fillers: preparation and their use in papermaking. Carbohydr Polym 81:545-553

Sun X, Mei C, French AD, Lee S, Wang Y, Wu Q (2018) Surface wetting behavior of nanocellulose-based composite films. Cellulose 25:5071-5087

Tang Z, Zhao M, Wang Y, Zhang W, Zhang M, Xiao H, Huang L, Chen L, Ouyang X, Zeng H, Wu H (2020) Musselinspired cellulose-based adhesive with biocompatibility and strong mechanical strength via metal coordination. Int J Biol Macromol 144:127-134

Trouiller B, Reliene R, Westbrook A, Solaimani P, Schiestl RH (2009) Titanium dioxide nanoparticles induce DNA damage and genetic instability in vivo in mice. Cancer Res 69:8784-8789

Wang S, Lu A, Zhang L (2016) Recent advances in regenerated cellulose materials. Prog Polym Sci 53:169-206

Wang Z, Dong L, Han L, Wang K, Lu X, Fang L, Qu S, Chan CW (2016) Self-assembled biodegradable nanoparticles and polysaccharides as biomimetic ECM nanostructures for the synergistic effect of RGD and BMP-2 on bone formation. Sci Rep 6:25090

Wang Z, Wang K, Zhang Y, Jiang Y, Lu X, Fang L, Gan D, Lv C, Zhang H, Qu S (2016) Protein-affinitive polydopamine nanoparticles as an efficient surface modification strategy for versatile porous scaffolds enhancing tissue regeneration. Part Part Syst Char 33:89-100

Wang Y, Su J, Li T, Ma P, Bai H, Xie Y, Chen M, Dong W (2017) A novel UV-shielding and transparent polymer film: when bioinspired dopamine-melanin hollow nanoparticles join polymers. ACS Appl Mater Interfaces 9:36281-36289

Wang C, Wang D, Dai T, Xu P, Wu P, Zou Y, Yang P, Hu J, Li Y, Cheng Y (2018) Skin pigmentation-inspired polydopamine sunscreens. Adv Funct Mater 28:1802127

Wang R, Wang X, Zhan Y, Xu Z, Xu Z, Feng X, Li S, Xu H (2019) A dual network hydrogel sunscreen based on poly$\gamma$-glutamic acid/tannic acid demonstrates excellent antiUV, self-recovery, and skin-integration capacities. ACS Appl Mater Interfaces 11:37502-37512

Wang S, Ma X, Zheng P (2019) Sulfo-functional 3D porous cellulose/graphene oxide composites for highly efficient removal of methylene blue and tetracycline from water. Int J Biol Macromol 140:119-128

White JD, Wilker JJ (2011) Underwater bonding with charged polymer mimics of marine mussel adhesive proteins. Macromolecules 44:5085-5088
Wu H, Wu L, Lu S, Lin X, Xiao H, Ouyang X, Cao S, Chen L, Huang L (2018) Robust superhydrophobic and superoleophilic filter paper via atom transfer radical polymerization for oil/water separation. Carbohydr Polym 181:419-425

Wu H, Li W, Zhao M, Lu S, Huang L, Chen L (2020) Progress in cellulose-based self-healing gels. J Forest Eng 5:11-17

Xiao H, Shan Y, Zhang W, Huang L, Chen L, Ni Y, Boury B, Wu H (2020) C-nanocoated ZnO by TEMPO-oxidized cellulose templating for improved photocatalytic performance. Carbohydr Polym 235:115958

Yin M-J, Yao M, Gao S, Zhang AP, Tam H-Y, Wai P-KA (2016) Rapid 3D patterning of poly(acrylic acid) ionic hydrogel for miniature $\mathrm{pH}$ sensors. Adv Mater 28:1394-1399

Yu JC, Yu J, Ho W, Jiang Z, Zhang L (2002) Effects of F-doping on the photocatalytic activity and microstructures of nanocrystalline $\mathrm{TiO}_{2}$ powders. Chem Mater 14:3808-3816

Zhang H, Bre LP, Zhao T, Zheng Y, Newland B, Wang W (2014) Mussel-inspired hyperbranched poly(amino ester) polymer as strong wet tissue adhesive. Biomaterials 35:711-719

Zhang X, Sun G-H, Tian M-P, Wang Y-N, Qu C-C, Cheng X-J, Feng C, Chen X-G (2019) Mussel-inspired antibacterial polydopamine/chitosan/temperature-responsive hydrogels for rapid hemostasis. Int J Biol Macromol 138:321-333

Zhao M, Tang Z, Zhang X, Li Z, Xiao H, Zhang M, Liu K, Ni Y, Huang L, Chen L, Wu H (2020) A self-healing, stretchable, and conductive poly(N-vinylpyrrolidone)/gallic acid composite hydrogel formed via hydrogen bonding for wearable electronic sensors. Compos Sci Technol 198:108294

Zhou J, Defante AP, Lin F, Xu Y, Yu J, Gao Y, Childers E, Dhinojwala A, Becker ML (2015) Adhesion properties of catechol-based biodegradable amino acid-based poly(ester urea) copolymers inspired from mussel proteins. Biomacromol 16:266-274

Zhou X, Lin X, White KL, Lin S, Wu H, Cao S, Huang L, Chen $L$ (2016) Effect of the degree of substitution on the hydrophobicity of acetylated cellulose for production of liquid marbles. Cellulose 23:811-821

Zhuo H, Hu Y, Tong X, Zhong L, Peng X, Sun R (2016) Sustainable hierarchical porous carbon aerogel from cellulose for high-performance supercapacitor and $\mathrm{CO}_{2}$ capture. Ind Crop Prod 87:229-235

Publisher's Note Springer Nature remains neutral with regard to jurisdictional claims in published maps and institutional affiliations. 